$\mathrm{BFJ}$

121,10

2396

Received 18 December 2018

Revised 5 May 2019

6 June 2019

Accepted 14 June 2019

\section{Consumer behaviour towards suboptimal food products: a strategy for food waste reduction}

\author{
Isadora do Carmo Stangherlin \\ Business School, Federal University of Rio Grande do Sul, Porto Alegre, Brazil \\ Jose Luis Duarte Ribeiro \\ Department of Industrial Engineering, \\ Federal University of Rio Grande do Sul, Porto Alegre, Brazil, and \\ Marcia Barcellos \\ Business School, Federal University of Rio Grande do Sul, \\ Porto Alegre, Brazil
}

\begin{abstract}
Purpose - Food waste has received attention during the last decade, especially due to its environmental and social impacts. An important contributor to food waste is consumers' low preference for purchase fruits and vegetables with unusual appearance, products with damaged package and products close to the expiration date, technically called suboptimal food products. Researches show that consumers tend to reject these products when buying food, increasing avoidable food waste. However, consumer considerations when deciding to buy or not to buy suboptimal food are still unknown. The purpose of this paper is to use two different approaches to investigate consumers' perceptions towards suboptimal food and how they impact their acceptance.

Design/methodology/approach - The first part of the study involved a qualitative analysis of participants' open-ended responses (282 answers), where participants were asked to write down the impressions they had about three suboptimal food images. The second phase explored consumers acceptance of suboptimal food through a focus group discussion.

Findings - Results reveal that considerations about suboptimal food are divergent, with some participants rejecting them because they are impelled to search for perfection when buying food products. However, some individuals are disposed to accept suboptimal products, mainly because they have concern with the environment and cook abilities.
\end{abstract}

Originality/value - As a whole, this study contributes for food waste reduction strategies and has implications for marketing actions.

Keywords Consumer choice, Food waste, Consumer food waste, Imperfect food, Suboptimal products Paper type Research paper

\section{Introduction}

Many areas of food systems can be improved to mitigate environmental impacts. An important aspect that has received increasing attention is related to food waste reduction. When food waste occurs, energy from agriculture, transportation, processing, food sales, storage, preparation and from the quality control activities throughout the supply chain are also wasted. Therefore, food waste represents a waste of resources (Kummu et al., 2012). One significant way of meeting such calls involves our food behaviour as consumers. An important contributor to food waste levels is consumers' preference for cosmetic standards (Parfitt et al., 2010). Individuals have a pattern of shopping behaviour in which only products with a certain visual characteristic are selected. However, this demand for "cosmetically perfect" food results in high levels of food waste and impacts the entire food supply chain.

Fruits and vegetables are selected mainly by their appearance (Marx-Pienaar and Erasmus, 2014), and deviations in the usual shape, size or weight cause rejection, even if 
they have the same intrinsic quality attributes and safety assurance (Göbel et al., 2015). With the same importance, packages with imperfections have also limited acceptance. When a package has a superficial damage, contamination cues are activated and preferences to purchase the products are lower (White et al., 2016). A similar pattern of behaviour that contributes to food waste levels is related to date labels (Milne, 2012). When expiration date is approaching or has passed, consumers reject the product mainly due to food safety and risk concern (Qi and Roe, 2016). Therefore, edible food is thrown away by farmers, producers, retailers and consumers due to a high demand for perfection. Products that do not meet specific cosmetic specifications are called suboptimal food products, representing fruits and vegetables with different visual appearance, food product with damaged packaging and food products close to the expiration date (de Hooge et al., 2017). Previous studies have discussed the low preference for suboptimal food (Aschemann-Witzel et al., 2015; de Hooge et al., 2017; Loebnitz and Grunert, 2015; Loebnitz et al., 2015; Tsiros and Heilman, 2005).

However, it is yet unknown which considerations consumers undertake when they have the opportunity to purchase suboptimal food. Why do individuals tend to reject these products? Do they always have negative thoughts when faced with suboptimal food products? Or do they also have some positive thoughts? How these considerations influence their buying behaviour? Trying to answer these questions, the main goal of this study is to explore consumers' considerations about suboptimal food products and how these impressions can influence their final decision.

An important limitation of previous research is that the study of consumer food waste is predominant in industrialized countries, with little research in developing ones (Parfitt et al., 2010). It is important to note that there is a great opportunity to achieve sustainable development reducing food waste in developing countries (Thi et al., 2015). This particular study analyses consumer food waste in Brazil. Food waste studies in this country are still incipient, but deserve attention (Porpino et al., 2015).

There is no regulation approved in Brazil to reduce food waste. However, it is possible to perceive a movement to change this fact (Matzembacher et al., 2018). Recently, the Intersectoral Strategy for Reduction of Food Losses and Waste in Brazil was launched, with the participation of public bodies, non-governmental organizations, universities, FAO, industry associations, supply centres and supermarkets (Matzembacher et al., 2018). It is known that Brazilian families waste an average of 353 grams of food per day or $128.8 \mathrm{~kg}$ per year. In a per capita analysis, the waste is 114 grams per day, representing an annual waste of $41.6 \mathrm{~kg}$ per person (Porpino et al., 2018). And the purpose of the action is to prevent and reduce 50 per cent of food losses and waste in Brazil by 2030 (Matzembacher et al., 2018). Therefore, it is important to study consumers' acceptance of different actions to reduce food waste levels. In this study, we consider the consumption and reduction of suboptimal food products as a strategy to reduce food waste.

This explorative study consisted of two different and complementary phases. In the first one, an open-ended question (part of an experimental study about food waste with Brazilian consumers) with thoughts generated by three different suboptimal products is analyzed. The second phase is a focus group discussion to expand the results of the first phase. Results of both phases show that consumers have divergent perceptions and opinions about suboptimal food products. Some participants tend to reject the products due to the fact that they search for perfection when buying food products. However, some of the participants tend to accept suboptimal food, mainly because they have concern with the environment and cook abilities. This study helps to understand relation between consumer behaviour and suboptimal food perceptions. In doing so, the study contributes to the evaluation of food waste reduction initiatives involving selling suboptimal food products, which has increased in the last years. 
$\mathrm{BFJ}$

121,10

2398

\section{Suboptimal food}

Food supply chain rejects food that deviate from the usual visual standards, even if its nutritional value remains the same (Göbel et al., 2015). This practice is considered an important contributor to food losses and waste (Gustavsson et al., 2011). First, it is important to distinguish between products that do not meet hygiene and quality requirements from food products with different visual appearance, but with the same nutritional quality (Salhofer $e t$ al., 2008). The first group is associated with safety issues, while the latter only is created due to market requirements, acting as barriers to food consumption (Hyde et al., 2001). Concerns regarding food safety and perceived risk are considered important aspects to food consumption (Galati, Moavero and Crescimanno, 2019), as well as for food waste issues (Canali et al., 2016). Nevertheless, consumers demand for food and packaging aesthetic appearance, selection of the freshest product and misinterpretation of date labels (Canali et al., 2016) equally represent a great impact on food waste levels.

It is known that there are many different variables and contexts that affect individuals to waste their food (Setti et al., 2016; Stangherlin and Barcellos, 2018). Setti et al. (2016) showed the links between "food purchasing and preparation practices" and "food storage practices and eating behaviour" as variables to explain consumer food waste. Stangherlin and Barcellos (2018) categorized the factors that affect consumers to waste into the categories societal factors, personal factors and behavioural factors, and some of the variables increase the amount of waste and some of them reduce it. Therefore, it is important to stimulate the variables that help to reduce food waste levels. Fiore $e t$ al. (2017) showed that interventions should be taken to alter choices of purchasing and consuming food. An important intervention that could be used to reduce food waste is the stimulus of suboptimal food consumption (de Hooge et al., 2017).

Suboptimal food products can be a result of natural variability, poor processing, physical or chemical reactions accelerated through incorrect handling (Raak et al., 2016). de Hooge et al. (2017) defined suboptimal food into three main variations in food's characteristics. The first includes variation on food appearance standards, food weight, shape or size, being cosmetically appealing or not. The second variation is related to food close to or beyond its best-before date. And the third variation is related to food packages with visual damages, such as a dented can or a torn wrapper (de Hooge et al., 2017). These deviations, however, do not represent safety risks and the food is still proper for human consumption.

The choice of suboptimal foods may occur in different environments (Aschemann-Witzel et al., 2015). When decisions are taken in supermarkets, consumers have the option to select or not the product, whereas decisions at household level food are already possessed (de Hooge et al., 2017). It is necessary, therefore, to define the context where the consumption of suboptimal food occurs. In the purchasing environment, creating accessibility, visibility and availability is essential (Hoek et al., 2017), opening markets to these products (Priefer et al., 2016). A major problem is that the judgment of foods' edibility varies significantly from person to person (Blichfeldt et al., 2015). Nevertheless, when presenting the same attributes, consumers tend to choose the ones with perfect appearance (Canali et al., 2016). The major problem is that this pattern of perfection creates a cycle of behaviour and, therefore, a cycle of waste.

Consumers demand information about the food that they are purchasing (Galati, Tulone, Moavero and Crescimanno, 2019), especially if they have concerns with food safety (Galati, Moavero and Crescimanno, 2019). Therefore, communication about characteristics of food, in our case suboptimal food, can shape consumers attitudes towards food products (Demartini et al., 2019).

It is possible to find a movement in order to change this pattern of behaviour and to increase the acceptance of suboptimal food products. The French retailer Intermaché created a campaign, called "inglorious" fruits and vegetables, Albert Heijn from the Netherlands used baskets of suboptimal fruits and vegetables to sell on their store, Imperfect redistribution from 
US sells boxes with suboptimal food (Aschemann-Witzel, de Hooge, Rohm, Normann, Bossle, Grønhøj and Oostindjer, 2017). The authors also analyzed food waste mitigation in Brazil. The study only identified food banks as waste reduction practices (Aschemann-Witzel, de Hooge, Rohm, Normann, Bossle, Grønhøj and Oostindjer, 2017). However, this aspect may change in the future. Few companies started to focus their business on food waste solutions for fruits and vegetables with unusual appearance (do Canto et al., 2017). The study analyzed a company that offers a signature delivery service of baskets with food that would be discarded by producers, either because they do not fit the aesthetic standard required, or because the food production exceeds market's demand, a restaurant that also provide a weekly delivery to consumers with foods as fresh and nutritious as the ones with an usual appearance and that manages the garbage (the dry garbage is thrown away only once a month and the organic waste is mostly used as input for composting or animal feed), and a community supported agriculture where consumers pay farmers in advance for a whole season's production, including imperfect foods (do Canto et al., 2017).

However, to these initiatives succeed, consumers must develop positive attitudes and behaviours towards these products. Attitudes towards suboptimal food might be linked to emotions (Rohm et al., 2017). However, it is important to explore deeply how these emotions occur. It is not clear yet which considerations of suboptimal food products consumers hold when they see these products. Moreover, it is not clear how these considerations can influence their final decision.

\section{Methodology}

Given the goal to research consumers' considerations about suboptimal food products, we used two different phases in this study. In the first phase, an open-ended question that captures perceptions about three suboptimal food products was analyzed (this question was part of an experimental study[1] about consumer food waste and suboptimal food products). The answers of the open-ended question were deeply analyzed in order to capture main thoughts and perceptions about three different suboptimal products. In the second phase of the study, we conducted a focus group discussion in order to deepen the results of the first phase and to capture different ideas about suboptimal food products with a different methodology.

In both phases, we showed to the participants pictures of three suboptimal food products, one for each type of suboptimality (de Hooge et al., 2017). To select a product with an unusual appearance, with a damaged package and a product close to the expiration date a pre-test was conducted, consisting of a short survey containing 11 different products, applied with a convenience sample $(n=21)$. The questionnaire was sent via social media and questions were about characteristics of the products.

First, it was analyzed the categories of products with higher levels of food waste in FAO's $(2013,2014)$ reports. The main categories presented in the reports were fruits, with 55 per cent of the fruits produced being wasted, and roots and tubers (40 per cent). Additionally, it was used the Analysis of Personal Food Consumption in Brazil (2008-2009) from the Brazilian Institute of Geography and Statistics (IBGE, 2011), to select products most consumed by Brazilian population. The analysis showed that the following categories of food are most consumed in Brazil: meet, milk and dairy products, baking and drinks and infusion. With fruits and vegetables, participants were asked to rate on a seven-point scale about the appearance of each product $(1=$ appearance very different from usual standard and $7=$ appearance very similar from usual standard). In the products with a damaged package and close expiration date, respondents were asked to rate on a seven-point scale about the ease to find a product in those conditions on the supermarket shelves $(1=$ very difficult to find and $7=$ very easy to find). The images considered suboptimal and used in the final study were: a carrot with unusual appearance; a biscuit damaged; and a package of yogurt with two days remaining to its expiration. In the following, the phases of the study are described. 
$\mathrm{BFJ}$
121,10

2400

\subsection{First phase}

In total, 282 Brazilian consumers were exposed to three different images of suboptimal food products, one for each type of suboptimality (see Table I for a sample characterization). The study was applied with students from a university of the south of Brazil in their classrooms $(n=127)$ and with general Brazilian consumers $(n=155)$, who received e-mailed invitations to participate in a survey about food consumption.

The survey was an experimental study about food waste and suboptimal food products. Participants received the following message:

Imagine you went to a supermarket to buy, among other things, the categories of products presented below. You visualized the products in the supermarket and found the following products.

One of the measures of the study asked participants to write down their thoughts after seeing the three the images of the products. This question was based on Melnyk et al. (2011) and intended to capture participants' perceptions about the images, what sometimes it is not possible to achieve with closed-ended questions. Also, it was captured the valence of the thoughts (positive and negative) that could influence the behaviour (Melnyk et al., 2011). To test the types of thoughts that the images activated, an open question was added, asking participants to list all the thoughts that they had in a box. These thoughts were coded as positive (when the thought supported the purchase of the products), negative (when the thought was against the purchase of the products) or neutral (when the thought mentioned something about the products but was neither in favour nor against it). Participants were free to express their major thoughts and comments about the images.

The open-ended question was analyzed in order to capture the perceptions about the products and to provide different insights to the analysis. A qualitative data analysis software MAXDQA was used to group the words into meaningful categories and automatically calculate their respective frequencies. As shown in Table II, consumers expressed their impressions about the three products together, grouped in the category suboptimal food, or expressed their perceptions about each product individually, grouped in the categories appearance, expiration date and/or package damaged. The categories were divided into factors where the valence of the thoughts was grouped together, some are related to acceptance of the products and others related to rejection. Expanding these factors, we created sub-factors to explore in details why consumers accept and/or reject the products.

Table II illustrates the frequencies of thoughts used to describe each product and categories. Note that these frequencies do not represent the number of the participants. They show the frequency that the comment emerged.

Sample size $(n)$

Gender N (\%)

Female

Table I.

Complete postgraduate

Incomplete postgraduate $\quad 8.2$

$\begin{array}{lr}\text { Complete higher education } & 10.3\end{array}$

Incomplete higher education $\quad 53.2$ 


\begin{tabular}{|c|c|c|c|c|c|}
\hline Category & Subcategories & $n$ & Sub-factors & $n$ & $\begin{array}{l}\text { Consumer } \\
\text { behaviour }\end{array}$ \\
\hline \multirow[t]{3}{*}{ Suboptimal food } & Acceptance & 27 & - & - & \\
\hline & Rejection & 77 & Poor quality & 15 & \\
\hline & & & Safety concerns & 2 & \\
\hline \multirow[t]{4}{*}{ Appearance } & Acceptance & 58 & Organic & 11 & \\
\hline & Rejection & 76 & Use of pesticides & $\begin{array}{r}18 \\
8\end{array}$ & 2401 \\
\hline & & & $\begin{array}{l}\text { Safety concerns } \\
\text { Lack of familiarity }\end{array}$ & $\begin{array}{r}8 \\
20\end{array}$ & 2401 \\
\hline & & & Ability to eat & 4 & \\
\hline \multirow[t]{3}{*}{ Expiration date } & Acceptance & 24 & - & - & \\
\hline & Rejection & 45 & Safety concerns & 15 & \\
\hline & Ability to eat & 52 & - & - & Table II. \\
\hline \multirow[t]{3}{*}{ Package damaged } & Acceptance & 32 & - & - & Content analysis of \\
\hline & Rejection & 101 & Safety concerns & 1 & thoughts towards \\
\hline & & & Poor handling & 19 & suboptimal food \\
\hline
\end{tabular}

\subsection{Second phase}

During June 2018, a focus group discussion was conducted in the south of Brazil. The focus group was performed with six participants, whereas the recommended number to focus group is between six and eight participants (Morgan, 1998). To increase sample diversity, the age range was 21-75 years old, participants came from different types of employment status, and different household composition (single, married or cohabiting; with or without children under 18 years in the household). Table III presents the socio-demographic profiling of the focus group participants. Participants were recruited by personal invitations using a standardized recruitment procedure: have already made purchases in supermarkets and being female. It was decided to select only women mainly because literature shows that they are usually the ones responsible for grocery shops and tend to have a more wasteful behaviour (Stangherlin and Barcellos, 2018).

Focus group was conducted according to standard procedures (Morgan and Krueger, 1993). There was a classroom with acoustic recording facilities. The focus group lasted $1 \mathrm{~h}$ and 5 min and was guided by a moderator. A topic guide was developed prior to the field work. The topic guide consisted of three main parts, following the overall objectives. The first one investigated respondents' opinion about the image of a carrot with an unusual appearance, the second part aimed at exploring respondents' perceptions about the image of a yogurt with two days remaining to expire and the third part explored participants' opinions towards an image of a package with a broken biscuit. The images were the same of the first phase of the study and each image was presented separately and participants reported their opinions about each of them. Participants were asked to state free associations and thoughts about the products. In the end, the moderator discussed with the participants main opinions emerged during the discussion.

\begin{tabular}{|c|c|c|c|c|c|}
\hline Participant & Age & Occupation & Education & Household composition & \\
\hline 1 & 31 & Accounting technician & Incomplete higher education & Single-household & \\
\hline 2 & 54 & Veterinarian & Complete higher education & Six-person household & \\
\hline 3 & 21 & Student & Incomplete higher education & Three-person household & \\
\hline 4 & 62 & Retired & High School complete & Two-person household & Table III. \\
\hline 5 & 75 & Retired & Complete higher education & Two-person household & Focus group \\
\hline 6 & 61 & Retired & Complete higher education & Single-household & participants \\
\hline
\end{tabular}


$\mathrm{BFJ}$ 121,10

\section{2}

Figure 1.

Framework with the perceptions about suboptimal food products
Focus group discussions were transcribed and analysis was performed with Microsoft Excel package. First, a list of codes was created across researchers. After coding transcription, researchers compared their coding lists and discussed the final codes. The transcript of the focus group was coded according to speared categories of sentences which reflected the content of these sentences. Each category contained information about one concept, in this case of each product analyzed, to detect trends about each product. Results are reported including verbatim statements showing opinions and beliefs of the participants.

In the end of the two phases of the research, two groups of analysis were performed. First, analyses were performed for each phase separately, which enabled summarizing participants' opinions and perceptions about the suboptimal food products. Second, both phases were analyzed together to capture main similarities and contrasts between both phases. These analyses provided insights into the correspondence between both results.

\section{Results}

In the sections that follow, we discuss the results of the first and the second phases of the study separately. In the end, a combined analysis investigating the correspondence between both phases is presented. Results of each phase are organized by themes emerged on data collection. A number of factors were mentioned by respondents after exposure to suboptimal food pictures. These factors are divided into the categories: suboptimal food products, with comments about the aspects of the three products in a general way, without any description of each product; product with an unusual appearance, with comments about the aspects of the carrot with a different appearance; product with reduced expiration date, encompassing comments about the yogurt with two days remaining to expire; and product with a package damaged, with comments about the broken biscuit.

\subsection{First phase}

An overview with the main factors and comments emerged in each category is presented in Figure 1. We organized each category (suboptimal food products, product with an unusual appearance, product with reduced expiration date, product with a package damaged) in subcategories, representing respondents' impressions about their acceptance or rejection towards the products. Moreover, an important issue that emerged in the comments was the possibility to eat the products because of its size, these comments were organized in the subcategory ability to eat the product and refers to respondents' concerns about the

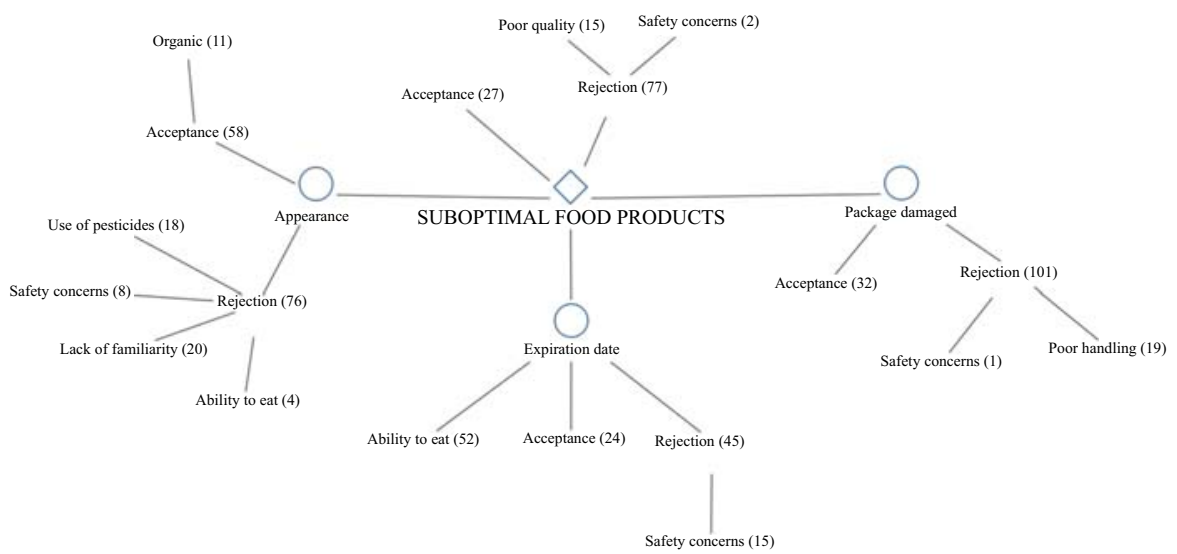


possibility of consuming the product due to its size (e.g. due to the fact that they live alone). If they recognized that they could not eat the product, they would not buy them:

I would not buy it because I found it too big for my consumption habits. (R157) (for the carrot with an unusual appearance)

4.1.1 Suboptimal food products acceptance. Some respondents recognize the difference in the appearance of the products but they would accept this difference and believe that the products are still good for consumption, for example:

Although they are "non-standard", this does not invalidate their use. (R3)

4.1.2 Suboptimal food products rejection. The majority of the respondents that expressed general comments about the products had negative thoughts, rejecting them and highlighting the importance of the standard appearance of the products:

Out of the normal standards of acceptance in the market. (R135)

When analyzing the respondents that would reject the products more closely, some comments are associated with quality issues, for example:

Under the conditions given, the products appear to have lower quality. (R165)

Respondents also mentioned concerns with the safety of the products:

Weird products, spoiled products, damaged products, defective products, products that cause damage or may cause damage. (R173)

4.1.3 Product with an unusual appearance acceptance. When faced with the carrot with unusual appearance, respondents had divergent opinions. Almost half of the comments were positive about the product. They recognize the difference in the appearance, but believe that the product is still suitable for consumption and would accept it:

The carrot was the most normal to me. I am aware that the traditional standard excludes "ugly" foods which, in a merely popular concept, are rejected because they are attributed to the poor quality of the product. (R18)

In some comments, respondents associated the carrot with different appearance with organic production, for example:

"I believe that a strange-shaped carrot has an idea of quality, maybe even be confused with something organic" (R25) and "The carrot, because it is not a traditional format, looks organic" (R59).

4.1.4 Product with an unusual appearance rejection. The great majority of the respondents had negative thoughts when visualizing the carrot with different appearance. The lack of familiarity with this product was mentioned as a factor that inhibited its consumption:

The carrot I found really different, such a reason for never having seen one like that in a supermarket, so maybe it would not take it. (R10)

Moreover, a different factor that caused rejection was related to concerns with the safety of the food, for example:

[...] making it available for public consumption can be a risky situation. (R162)

Additionally, respondents associated the carrot with excessive use of pesticides:

I was very reticent about the carrot, because to me it seemed to be defective due to the excessive use of pesticides. (R38) 
$\mathrm{BFJ}$

121,10

4.1.5 Product with reduced expiration date acceptance. When analyzing the thoughts about the yogurt with a reduced expiration date, few respondents mentioned that they would accept the product and that the two days remaining to expire would not affect their decision:

It does not interfere anything, since the expiration date is a protective factor and not determinative. (R145)

4.1.6 Product with reduced expiration date rejection. The great majority of the respondents rejected the product due to its reduced expiration date, claiming that they would search for a different one, for example:

I consume this product almost every day, but with the tight expiration date I would look for another on the shelf with a longer shelf life. (R157)

Furthermore, respondents were concerned about the safety of the product:

It can cause health problems because it is about to expire. (R159)

A number of respondents referred to the issue of the ability to consume the product within two days. This was a significant factor to accept or not the product. If respondents knew that they could consume the product soon, they accepted it. If they bought it to consume in a longer period, they tended to reject it:

"I believe that my decision to buy the yogurt varies according to my idea of consumption: if my idea is to consume today [...] I would buy. If I do not know when I will consume, I would look for one with a longer expiration date" (R31) and "Yogurt is near the expiration date, but is still within the expiration date, so no problem to consume in a short time" (R20).

4.1.7 Product with a package damaged acceptance. About the product with a damaged package, some respondents would accept the product. These respondents recognized that the package was not perfect; however, this fact did not influence their decisions:

Considering the situation of the biscuit, I do not see any problem in its consumption if it were available for purchase. The issue of having only a few broken biscuits, with the apparent packaging in good condition, does not generally affect the quality of the product. (R162).

4.1.8 Product with a package damaged rejection. The great majority of the respondents had negative thoughts about this product, rejecting it:

Regarding the biscuit, even knowing that it presents no problem, I would not buy because I would be "losing" the product. (R164)

Some negative comments were about the poor handling of the product, for example:

Product broken, impression to be thrown, manipulated incorrectly. (R159)

One of the respondents expressed concerns with the safety of the food:

In the case of damaged packaging, I would not buy because this could mean both a loss of quality and a risk to the health of the consumer. (R15)

Based on these observations, we derived a figure visualizing the factor division between the factors, showing the valence of the thoughts (acceptance vs rejection) and the factors most commented in each division (see Figure 1). The numbers in each factor represent the frequency of the comment.

\subsection{Second phase}

In the following section, the main findings of the focus group discussion are reported. To report the results, we used the same categories of the previous phase, except for the category 
suboptimal food products, due to the fact that the focus discussion focused on each product individually. In this way, the categories of the results are: product with an unusual appearance, product with reduced expiration date and product with a package damaged.

4.2.1 Product with an unusual appearance. When analyzing the carrot with unusual appearance, the great majority of the participants mentioned that they would buy it. They mentioned the different appearance; however, they believe that the carrot is similar with others. Some respondents mentioned the fact that the product came from the nature:

I think it's normal because I think in nature, for example, we have a potato, one stuck in the other, from the soil in places where no fertilizer is used [...] so I think it's [...] the essence of nature, which is not normal, but is a carrot. (R6)

Additionally, an association with the production method was mentioned:

I would buy [...] but I would question what kind of fertilizer was used to grow that way, which was, of course, different. (R4)

According to the participants, even accepting the product, they recognize that humans tend to search for perfection when buying products, for example:

It is that the human being tends to go in the standard. It's kind of natural, so you look "ah, no, this is not expected [...]". (R1)

Furthermore, some respondents mentioned the importance of distinguish where the purchase occurs. When buying in supermarkets, it is more common to have only food with standard appearance:

You can also observe, in the supermarket, they have more or less the same size, more or less the same texture. (R6)

However, this fact may change if the purchase occurs in local fairs:

You go to the fair what you have there is what is there, it is rustic, comes with dirt, comes without dirt [...]. (R4)

Some respondents would not buy the carrot, mainly because its size or different appearance:

I would buy if I had no other option [...] but if there were other normal ones together, I would buy the others, I would not accept that [...]. (R2)

4.2.2 Product with reduced expiration date. About the yogurt with reduced expiration date, the great majority of the participants stated that they would buy the yogurt, mainly because they could consume the product in the same day or use it with different recipes:

"[...] I probably buy it and I'll eat it at the same time." (R1) and "If I were to make a recipe or something and I'm sure I would do on that day or the other [...] then I would buy, no problem at all." (R3)

Some respondents mentioned that they already used products expired in their households, for example:

Mainly because sometimes you eat expired at home and it's good anyway. (R3)

However, they stated that they would not buy the product if it was already expired:

"If I see that it's expired, I will not buy it [...]" (R1) and "I look for maximum durability until expire." (R6)

When buying food products, some respondents mentioned that they select the ones with the longest expiration date:

I get the newest one [...]. (R2)

Consumer behaviour 
$\mathrm{BFJ}$

121,10

2406

Respondent 6 mentioned important aspects to reject the product: she would not consume the yogurt in the same day; and if her family was bigger, she would buy the product. However, as she lives alone, she would not buy it. Moreover, Respondent 6 mentioned a concern with her health, even when she has an expired product in her household:

I through it out, no matter the price, because my health is priceless, right, I will not risk my health, not at all.

4.2.3 Product with a package damaged. When asked about the broken biscuit, participants had divergent impressions. One participant had a negative emotion towards the product with a damaged package:

I would not buy because I think conservation changes. A dented can, I think it changes. A crumpled cardboard box, I think it changes. I do not buy. (R6)

However, the great majority sad that they would buy the product, but with a certain limit, for example:

It depends on the kneading. I think if it's only a bit you do not have to stop buying. (R3)

It is important to observe that some participants mentioned that they were willing to buy the products depending on what they plan to do with it:

If you're going to make a pie it is fine. If it's to consume like a biscuit, I would buy the whole thing. (R2)

\section{Discussion}

This study presents original findings on consumers' perceptions towards suboptimal food products. Results of both phases showed similarities between the factors emerged towards the products. However, in the first phase, individuals had more negative (rejection) than positive (acceptance) impressions towards the products. This occurs due to the fact that respondents search for the "perfect" appearance when buying food products and associated it with product quality (Aschemann-Witzel et al., 2015). Moreover, it seems that individuals want to maximize their purchases, and when buying suboptimal food, they feel that they are losing some aspects of the product.

In the second phase, participants were more willing to accept the products. Results from the focus group discussion showed that participants are more connected with food and food preparation and, therefore, tend to accept the products. Previous studies show that developed cooking skills (Gjerris and Gaiani, 2013; Mylan et al., 2016; Graham-Rowe et al., 2014; Ponis et al., 2017) and better understanding of foods' edibility reduce the amount of waste (Farr-Wharton et al., 2014). Additionally, connection with food is a key driver to reduce food waste (Blichfeldt et al., 2015). Participants that are more aware of the importance of food and know different ways to prepare it are more proactive to reduce waste accepting suboptimal products.

Table IV presents an overview of the main perceptions emerged in both phases.

An important factor that emerged in both phases was the production method of the carrot with an unusual appearance. Some respondents believed that the product had more pesticides and chemical use and, therefore, would not buy it. However, there is a tendency to accept this product if the product has an organic production credential. Consumers tend to accept cosmetically imperfect food after provisioning information about reduced use of pesticides (Bunn et al., 1990). Moreover, branding the product as organic have benefits to the company, promoting positive brand associations (White et al., 2016).

Moreover, it was possible to note that when individuals have higher concern for the environment, they are more open to cosmetically imperfections (Yue et al., 2009). 


\begin{tabular}{|c|c|c|}
\hline First phase & Second phase & Consumer \\
\hline \multicolumn{3}{|l|}{ Product with unusual appearance } \\
\hline Organic production & Product from nature & \\
\hline Use of pesticides & Production method & \\
\hline Lack of familiarity & Search for perfection & \\
\hline Ability to eat & Product size & 2,07 \\
\hline \multirow{4}{*}{$\begin{array}{l}\text { Product with reduced expiration date } \\
\text { Ability to eat }\end{array}$} & & 2408 \\
\hline & Consume in the same day & \\
\hline & Household size & \\
\hline & Maximum durability & \\
\hline Safety concerns & Health issues & \\
\hline \multicolumn{3}{|l|}{ Product with damaged package } \\
\hline Safety concerns & Product conservation & \\
\hline \multirow{2}{*}{ Poor handling } & Limit of acceptance & Table IV. \\
\hline & Use in recipes & Results summary \\
\hline
\end{tabular}

Results show that when individuals had connection with nature, they were more open to accept the suboptimal products (Blichfeldt et al., 2015). Specifically in the focus group discussion, respondents that had a proximity with the nature and the natural production of the food were prone to accept the carrot with an unusual appearance:

I think it's normal because I think in nature [...]. (R6)

However, when respondents do not have knowledge to drawn inferences about the product and its condition to eat, individuals tend to rely on food appearance, smell or taste to judge its edibility (Graham-Rowe et al., 2014; Lazell, 2016) and, therefore, tend to reject the products. For example, the lack of familiarity with the carrot with unusual appearance produced negative perceptions towards the product.

An important aspect emerged about the yogurt with a reduced expiration date was the fact that before accepting the product, respondents considered if they would be able to eat it within two days. If they could eat the yogurt before it expires, they were prone to accept it. However, they tended to reject if they could not include the product in their eating routine. Some of the respondents would avoid buying it in order to not throw the product away in their households. This is an important aspect, whereas consumers tend to avoid the purchase of the products when they know that the food waste may occur in the household level (Graham-Rowe et al., 2014; Stefan et al., 2013).

Different considerations were also mentioned about the yogurt with two days to expire. In the focus group discussion, the household size was an important factor considered (Jörissen et al., 2015; Silvennoinen et al., 2014; Tucker and Farrelly, 2016). For bigger households, to eat the product with a reduced expiration date seemed to be easier than for smaller ones. Moreover, safety concerns were also an important factor described by the participants. Some individuals justify their rejection of the product with a reduced expiration date mentioning safety and risk concerns (Graham-Rowe et al., 2014; Lazell, 2016; Abdelradi, 2018). A better understanding of the food edibility can help in the acceptance of suboptimal products and, therefore, help in food waste reduction (Farr-Wharton et al., 2014; Blichfeldt et al., 2015).

The product with a damaged package had the lowest acceptance in the first phase of the study. This fact occurred mainly by respondents' necessity of buying products in perfect conditions. de Hooge et al. (2017) showed that individuals hardly accept to buy broken biscuits when they are in the supermarket. When visualizing this product, contamination cues may be activated (White et al., 2016), which impacted in their final perceptions. 
$\mathrm{BFJ}$

121,10

2408

Moreover, quality dimension (Grunert, 2007) is an important factor that contributed to its rejection. The broken biscuit was associated with poor quality and also poor handling, which impacts its quality perception.

However, for the individuals that knew what to do with the product the acceptance was higher. Some of the respondents mentioned that they could use the broken biscuit in different recipes and, therefore, would buy it. Here, the results show again that who has cooking skills have higher acceptance towards suboptimal food products and, therefore, help in food waste reduction (Gjerris and Gaiani, 2013; Mylan et al., 2016; Graham-Rowe et al., 2014; Ponis et al., 2017).

Results reinforce the importance of appropriate communication towards the products. When selling suboptimal food products, they must be accompanied by communication of their safety, as products still suitable for consumption and how rejecting them can increase food waste levels. Additional effort can be directed to convince consumers that the products have the same attributes of taste, flavour and smell (Symmank et al., 2018). This practice can be explored with practical interventions, such as sensory skills (Principato et al., 2015), increasing freshness and expiration date awareness. Moreover, it is important to create awareness about the importance of connection with food and nature, in trying to increase individuals' environmental concern. Finally, results showed the importance of providing different recipes and help individuals to use food products. Participants that knew how to use the products tended to have a higher acceptance of suboptimal food than the ones that did not know. These observations can help in building strategies for reducing food waste.

\section{Conclusions and limitations of the study}

It is increasing discussion about the importance of consumers change their usual behaviours to cope with more sustainable practices. A way to achieve this is through purchase of suboptimal food, since preferences for these products affect both retailer and consumer food waste (Aschemann-Witzel et al., 2015). Findings show the extent to which suboptimal food choice is impacted by various factors. The results particularly highlight significant differences in perceptions about these products. Moreover, there was not a pattern of behaviour: some consumers would accept one product and reject the others, while other consumers would accept or reject all of them. This shows the importance of analyzing the results for each product individually, whereas the acceptance of suboptimal food depends on the type of suboptimality (de Hooge et al., 2017).

This research holds important implications for advertisers and marketing strategies. Campaign designers could use normative influences in trying to communicate the importance of consuming suboptimal food. Again, it is important to create awareness that rejection of these products significantly increases avoidable food waste.

Additionally, retailers need to create a good brand image and trust in food safety (Aschemann-Witzel, de Hooge, Rohm, Normann, Bossle, Grønhøj and Oostindjer, 2017). Since some individuals believe that the two days to expire or a few broken biscuits do not invalidate their consumption, retailers can create the right context where more consumers perceive value in these products. Consumers' decision making regard suboptimal food can be positively influenced if they are provided with the appropriate message for that.

This study has implications for retailers by showing what consumers consider when has the possibility of buying suboptimal food products. For brand marketing strategies, results show different directions that could be used in order to increase consumers' acceptance towards the products. And the study also has implications for policy makers, indicating the importance of providing educational strategies addressed to consumer, by raising awareness of the importance of reducing food waste levels and what strategies individuals could have to achieve this end (such as buying and consuming suboptimal products). Indeed, results are considered useful for inspiring the correct framing of a message. 
It is important to note that the qualitative findings have to be interpreted with the limitations of the data. The method might to some degree triggers thoughts that under normal circumstances would not have come to mind to that extent. Interpretation of such data should focus on the relation of the factors. Future research could provide greater insight into the issue by using different methods of data collection and trying to analyze suboptimal food perceptions under different circumstances. Also, future studies could analyze how personal variables, such as age, educational level, sex, interact with the results. Maybe some interesting correlations between the results and these variables could provide richer analyses.

Another limitation of the study was the fact that we did not considered the price of the products. It seems that price focus consumers have lower levels of food waste (AschemannWitzel, Jensen, Jensen and Kulikovskaja, 2017). However, it was not the purpose of this study to consider the variable price. Results may vary when considering price positioning as a strategy to sell suboptimal food. Nevertheless, in the case of expiration date pricing strategies, it is important to increase familiarity with the practice to influence individuals (AschemannWitzel, 2018). However, the recent study showed that some interventions, such as to alter self-perceptions, eliminate the need to discount unattractive foods (Grewal et al., 2019).

Finally, a different limitation of the study was the fact that we did not control if respondents were responsible for food purchases in their households. This may affect the results, whereas if they were not the responsible for grocery shops, they may not have this type of considerations. We highlight this as a recommendation for future studies, in order to investigate if this variable (being the responsible for food purchases) would affect the acceptance of suboptimal food.

\section{Note}

1. The results of the quantitative data are explored in a different study and are part of a master's thesis.

\section{References}

Abdelradi, F. (2018), "Food waste behaviour at the household level: a conceptual framework", Waste Management, Vol. 71, January, pp. 485-493.

Aschemann-Witzel, J. (2018), "Consumer perception and preference for suboptimal food under the emerging practice of expiration date based pricing in supermarkets", Food Quality and Preference, Vol. 63, January, pp. 119-128.

Aschemann-Witzel, J., Jensen, J.H., Jensen, M.H. and Kulikovskaja, V. (2017), "Consumer behaviour towards price-reduced suboptimal foods in the supermarket and the relation to food waste in households", Appetite, Vol. 116, September, pp. 246-258.

Aschemann-Witzel, J., de Hooge, I., Amani, P., Bech-Larsen, T. and Oostindjer, M. (2015), "Consumerrelated food waste: causes and potential for action", Sustainability, Vol. 7 No. 6, pp. 6457-6477.

Aschemann-Witzel, J., de Hooge, I.E., Rohm, H., Normann, A., Bossle, M.B., Grønhøj, A. and Oostindjer, M. (2017), "Key characteristics and success factors of supply chain initiatives tackling consumerrelated food waste - a multiple case study", Journal of Cleaner Production, Vol. 155, Part 2, pp. 33-45.

Blichfeldt, B.S., Mikkelsen, M. and Gram, M. (2015), "When it stops being food. Food, culture \& society", An International Journal of Multidisciplinary Research, Vol. 18 No. 1, pp. 89-105.

Bunn, D., Feenstra, G.W., Lynch, L. and Sommer, R. (1990), "Consumer acceptance of cosmetically imperfect produce”, Journal of Consumer Affairs, Vol. 24 No. 2, pp. 268-279.

Canali, M., Amani, P., Aramyan, L., Gheoldus, M., Moates, G., Ã-Stergren, K., Silvennoinen, K., Waldron, K. and Vittuari, M. (2016), "Food waste drivers in Europe, from identification to possible interventions", Sustainability, Vol. 9 No. 1, p. 37. 
$\mathrm{BFJ}$

121,10

de Hooge, I.E., Oostindjer, M., Aschemann-Witzel, J., Normann, A., Loose, S.M. and Almli, V.L. (2017), "This apple is too ugly for me!: consumer preferences for suboptimal food products in the supermarket and at home", Food Quality and Preference, Vol. 56, Part A, pp. 80-92.

Demartini, E., Gaviglio, A., La Sala, P. and Fiore, M. (2019), "Impact of information and food technology neophobia in consumers' acceptance of shelf-life extension in packaged fresh fish fillets", Sustainable Production and Consumption, Vol. 17, January, pp. 116-125.

do Canto, N.R., Stangherlin, I.C., Eckert, D., Alves, A.P.F. and Barcellos, M.D. (2017), Food Waste Solutions in Sustainability Strategy: A Multiple Case Study with Brazilian Companies, Anais do XLI Encontro da ANPAD, São Paulo.

FAO (2013), "Urgent collaboration required on food wastage", available at: www.fao.org/news/story/ en/item/202914/icode/ (accessed 12 March 2017).

FAO (2014), "FAO statistical yearbook 2014 - Latin America and the Caribbean food and agriculture", FAO, Santiago.

Farr-Wharton, G., Foth, M. and Choi, J.H.J. (2014), "Identifying factors that promote consumer behaviours causing expired domestic food waste", Journal of Consumer Behaviour, Vol. 13 No. 6, pp. 393-402.

Fiore, M., Pellegrini, G., Sala, P.L., Conte, A. and Liu, B. (2017), “Attitude toward food waste reduction: the case of Italian consumers", International Journal of Globalisation and Small Business, Vol. 9 Nos 2-3, pp. 185-201.

Galati, A., Moavero, P. and Crescimanno, M. (2019), "Consumer awareness and acceptance of irradiated foods: the case of Italian consumers", British Food Journal, Vol. 121 No. 6, pp. 1398-1412.

Galati, A., Tulone, A., Moavero, P. and Crescimanno, M. (2019), "Consumer interest in information regarding novel food technologies in Italy: the case of irradiated foods", Food Research International, Vol. 119, pp. 291-296.

Gjerris, M. and Gaiani, S. (2013), "Household food waste in Nordic countries: estimations and ethical implications", Etikk i praksis-Nordic Journal of Applied Ethics, Vol. 7 No. 1, pp. 6-23.

Göbel, C., Langen, N., Blumenthal, A., Teitscheid, P. and Ritter, G. (2015), "Cutting food waste through cooperation along the food supply chain”, Sustainability, Vol. 7 No. 2, pp. 1429-1445.

Graham-Rowe, E., Jessop, D.C. and Sparks, P. (2014), "Identifying motivations and barriers to minimising household food waste”, Resources, Conservation and Recycling, Vol. 84, March, pp. 15-23.

Grewal, L., Hmurovic, J., Lamberton, C. and Reczek, R.W. (2019), “The self-perception connection: why consumers devalue unattractive produce”, Journal of Marketing, Vol. 83 No. 1, pp. 89-107.

Grunert, K.G. (2007), "How consumers perceive food quality: in understanding consumers of food products", British Welding Research Association, pp. 181-199.

Gustavsson, J., Cederberg, C., Sonesson, U., van Otterdijk, R. and Meybeck, A. (2011), Global Food Losses and Food Waste: Extent Causes and Prevention, Food and Agriculture Organization (FAO) of the United Nations, Rome.

Hoek, A.C., Pearson, D., James, S.W., Lawrence, M.A. and Friel, S. (2017), "Shrinking the food-print: a qualitative study into consumer perceptions, experiences and attitudes towards healthy and environmentally friendly food behaviours", Appetite, Vol. 108, January, pp. 117-131.

Hyde, K., Smith, A., Smith, M. and Henningsson, S. (2001), "The challenge of waste minimisation in the food and drink industry: a demonstration project in East Anglia, UK”, Journal of Cleaner Production, Vol. 9 No. 1, pp. 57-64.

IBGE (2011), "Pesquisa de Orçamentos Familiares 2008-2009: análise do consumo alimentar pessoal no Brasil”, Instituto Brasileiro de Geografia e Estatística, Rio de Janeiro, available at: www.ibge.gov. br/home/estatistica/populacao/condicaodevida/pof/2008_2009_analise_consumo/pofanalise_200 8_2009.pdf (accessed May 2018).

Jörissen, J., Priefer, C. and Bräutigam, K.R. (2015), "Food waste generation at household level: results of a survey among employees of two European research centers in Italy and Germany", Sustainability, Vol. 7 No. 3, pp. 2695-2715. 
Kummu, M., De Moel, H., Porkka, M., Siebert, S., Varis, O. and Ward, P.J. (2012), "Lost food, wasted resources: global food supply chain losses and their impacts on freshwater, cropland, and fertiliser use", Science of the Total Environment, Vol. 438, November, pp. 477-489.

Lazell, J. (2016), “Consumer food waste behaviour in universities: sharing as a means of prevention”, Journal of Consumer Behaviour, Vol. 15 No. 5, pp. 430-439.

Loebnitz, N. and Grunert, K.G. (2015), "The effect of food shape abnormality on purchase intentions in China”, Food Quality and Preference, Vol. 40, Part A, pp. 24-30.

Loebnitz, N., Schuitema, G. and Grunert, K.G. (2015), "Who buys oddly shaped food and why? Impacts of food shape abnormality and organic labelling on purchase intentions", Psychology \& Marketing, Vol. 32 No. 4, pp. 408-421.

Marx-Pienaar, N.J. and Erasmus, A.C. (2014), "Status consciousness and knowledge as potential impediments of households' sustainable consumption practices of fresh produce amidst times of climate change", International Journal of Consumer Studies, Vol. 38 No. 4, pp. 419-426.

Matzembacher, D.E., de Barcellos, M.D. and Vieira, L.M. (2018), "De um limão, uma limonada", GV-executivo, Vol. 17 No. 6.

Melnyk, V., Herpen, E.V., Fischer, A.R. and van Trijp, H.C. (2011), “To think or not to think: the effect of cognitive deliberation on the influence of injunctive versus descriptive social norms", Psychology \& Marketing, Vol. 28 No. 7, pp. 709-729.

Milne, R. (2012), "Arbiters of waste: date labels, the consumer and knowing good, safe food", The Sociological Review, Vol. 60 No. S2, pp. 84-101.

Morgan, D. and Krueger, R.A. (1993), "When to use focus groups and why", in Morgan, D. (Ed.), Successful Focus Groups: Advancing the State of the Art, Sage Publications, Newbury Park, CA and London, pp. 3-19.

Morgan, D.L. (1998), The Focus Group Guidebook, Sage Publications, London.

Mylan, J., Holmes, H. and Paddock, J. (2016), “Re-introducing consumption to the 'circular economy': a sociotechnical analysis of domestic food provisioning", Sustainability, Vol. 8 No. 8, p. 794.

Parfitt, J., Barthel, M. and Macnaughton, S. (2010), "Food waste within food supply chains: quantification and potential for change to 2050", Philosophical Transactions of the Royal Society B: Biological Sciences, Vol. 365 No. 1554, pp. 3065-3081.

Ponis, S.T., Papanikolaou, P.A., Katimertzoglou, P., Ntalla, A.C. and Xenos, K.I. (2017), "Household food waste in Greece: a questionnaire survey”, Journal of Cleaner Production, Vol. 149, April, pp. 1268-1277.

Porpino, G., Parente, J. and Wansink, B. (2015), "Food waste paradox: antecedents of food disposal in low income households", International Journal of Consumer Studies, Vol. 39 No. 6, pp. 619-629.

Porpino, G., Lourenço, C.E., Araújo, C.M. and Bastos, A. (2018), "Intercâmbio Brasil - União Europeia sobre desperdício de alimentos”, Relatório final de pesquisa, Diálogos Setoriais União Europeia Brasil. Brasilia, available at: www.sectordialogues.org/publicacao

Priefer, C., Jörissen, J. and Bräutigam, K.R. (2016), "Food waste prevention in Europe - a cause-driven approach to identify the most relevant leverage points for action", Resources, Conservation and Recycling, Vol. 109, May-June, pp. 155-165.

Principato, L., Secondi, L. and Pratesi, C.A. (2015), "Reducing food waste: an investigation on the behaviour of Italian youths”, British Food Journal, Vol. 117 No. 2, pp. 731-748.

Qi, D. and Roe, B.E. (2016), "Household food waste: multivariate regression and principal components analyses of awareness and attitudes among US consumers", PloS One, Vol. 11 No. 7.

Raak, N., Symmank, C., Zahn, S., Aschemann-Witzel, J. and Rohm, H. (2016), "Processing-and productrelated causes for food waste and implications for the food supply chain", Waste Management, Vol. 61, March, pp. 461-472.

Rohm, H., Oostindjer, M., Aschemann-Witzel, J., Symmank, C., Almli, V.L., de Hooge, I.E., Normann, A. and Karantininis, K. (2017), "Consumers in a sustainable food supply chain (COSUS): understanding consumer behavior to encourage food waste reduction", Foods, Vol. 6 No. 12, p. 104. 
$\mathrm{BFJ}$

121,10

Salhofer, S., Obersteiner, G., Schneider, F. and Lebersorger, S. (2008), "Potentials for the prevention of municipal solid waste", Waste Management, Vol. 28 No. 2, pp. 245-259.

Setti, M., Falasconi, L., Segrè, A., Cusano, I. and Vittuari, M. (2016), "Italian consumers' income and food waste behavior", British Food Journal, Vol. 118 No. 7, pp. 1731-1746.

Silvennoinen, K., Katajajuuri, J.M., Hartikainen, H., Heikkilä, L. and Reinikainen, A. (2014), "Food waste volume and composition in Finnish households", British Food Journal, Vol. 116 No. 6, pp. 1058-1068.

Stangherlin, I.C. and Barcellos, M.D. (2018), "Drivers and barriers to food waste reduction”, British Food Journal, Vol. 120 No. 10, pp. 2364-2387.

Stefan, V., van Herpen, E., Tudoran, A.A. and Lähteenmäki, L. (2013), "Avoiding food waste by Romanian consumers: the importance of planning and shopping routines", Food Quality and Preference, Vol. 28 No. 1, pp. 375-381.

Symmank, C., Zahn, S. and Rohm, H. (2018), "Visually suboptimal bananas: how ripeness affects consumer expectation and perception", Appetite, Vol. 120, January, pp. 472-481.

Thi, N.B.D., Kumar, G. and Lin, C.Y. (2015), "An overview of food waste management in developing countries: current status and future perspective", Journal of Environmental Management, Vol. 157, July, pp. 220-229.

Tsiros, M. and Heilman, C.M. (2005), "The effect of expiration dates and perceived risk on purchasing behavior in grocery store perishable categories", Journal of Marketing, Vol. 69 No. 2, pp. 114-129.

Tucker, C.A. and Farrelly, T. (2016), "Household food waste: the implications of consumer choice in food from purchase to disposal", Local Environment, Vol. 21 No. 6, pp. 682-706.

White, K., Lin, L., Dahl, D.W. and Ritchie, R.J. (2016), "When do consumers avoid imperfections? Superficial packaging damage as a contamination cue", Journal of Marketing Research, Vol. 53 No. 1, pp. 110-123.

Yue, C., Alfnes, F. and Jensen, H.H. (2009), 'Discounting spotted apples: investigating consumers' willingness to accept cosmetic damage in an organic product", Journal of Agricultural and Applied Economics, Vol. 41 No. 1, pp. 29-46.

\begin{abstract}
About the authors
Isadora do Carmo Stangherlin is PhD Student of Business School, Federal University of Rio Grande do Sul. Her main research interests include consumer behaviour, food waste, food waste reduction, food marketing, consumer food purchasing behaviour and sustainability. Isadora do Carmo Stangherlin is the corresponding author and can be contacted at: isadoradocarmostangherlin@gmail.com

Jose Luis Duarte Ribeiro is currently Full Professor at the Industrial Engineering Department, Federal University of Rio Grande do Sul, where he coordinates the Office of Technological Development (SEDETEC/UFRGS). From 1998 to 2001, he was President of the Brazilian Society for Industrial Engineering. He is author of numerous works on innovation, sustainability, product development, quality engineering, reliability and quantitative methods applied to industrial engineering published in international journals and conference proceedings.

Marcia Barcellos, PhD is Professor of Business School, Federal University of Rio Grande do Sul. She is Director of the Center for Studies and Research in Administration (CEPA/UFRGS); Member of the Coordinating Committee of the Postgraduate Program in Administration (PPGA/UFRGS); and Leader of the CNPq Consumer Research Group. Her main research interests are consumer behaviour of agri-food products, competitiveness, innovation, marketing, agribusiness and sustainability.
\end{abstract}

For instructions on how to order reprints of this article, please visit our website:

www.emeraldgrouppublishing.com/licensing/reprints.htm

Or contact us for further details: permissions@emeraldinsight.com 